\section{Illness perception, stress, religiosity, depression, social support, and self management of diabetes in Indonesia}

\author{
Yuniarti, Kwartarini Wahyu \\ Department of Magister of Professional Psychology, Faculty of Psychology, Universitas Gadjah Mada, \\ Yogyakarta, Indonesia (kwartarini_yuniarti@yahoo.com)
}

\section{Dewi, Citra}

Department of Magister of Professional Psychology, Faculty of Psychology, Universitas Gadjah Mada, Yogyakarta, Indonesia (cidew86@gmail.com)

Ningrum, Retno Prasetyo

Department of Magister of Professional Psychology, Faculty of Psychology, Universitas Gadjah Mada, Yogyakarta, Indonesia (none_littlegirl@yahoo.com)

\section{Widiastuti, Mariyana}

Department of Magister of Professional Psychology, Faculty of Psychology, Universitas Gadjah Mada, Yogyakarta, Indonesia (dhee psyche@yahoo.co.id)

Asril, Nice Maylani

Department of Magister of Professional Psychology, Faculty of Psychology, Universitas Gadjah Mada, Yogyakarta, Indonesia (nicemaylani@yahoo.com)

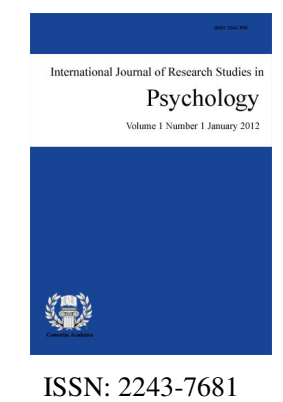
Online ISSN: 2243-769X

OPEN ACCESS

\title{
Abstract
}

This is an integration of three studies on type 2 diabetes. In this study, diabetes was seen in relation to illness perception, stress, depression, social support, and self management. The studies conducted using quantitative approach, employing 68 participants, aged between 40-75 years old. Interviewer-administered questionnaires were used for the data collection. Sobel test was employed to examine the mediation states of the variables in the three quantitative studies, and regression analysis was then executed for hypotheses testing. Results show that self-acceptance were significantly related to depression (r:-.14, $p<.05)$ without being mediated by perceived social support (r:-.16, p>.05). Religiosity approved to be significantly related to the stress (r:-.69, $p<.05)$, mediated by self acceptance (r:-.36, $p<.05$ ). "Easily being tired in work, compared to the previous condition" was identified by most of the study participants as the cause of stress. It was also discovered that illness perception and coping strategies were not having a direct association with self-management in general. This study suspected that there was multicollinearity among 8 sub-components of illness perception, coping strategies and self-management. Conclusion: self-acceptance is the most important among others; and that participants, with family, need to have correct knowledge on the nature of the illness and its management.

Keywords: diabetes mellitus; self-management; psychosocial aspect; depression; social support; self-acceptance; religiosity; anxiety; illness perception; peer support 


\section{Illness perception, stress, religiosity, depression, social support, and self management of diabetes in Indonesia}

\section{Introduction}

Towards a Healthy Indonesia in 2010 is a program which seeks to improve Indonesian society through the development of public health, on a national and state level, that is characterized by living in healthy environments and engaging in healthy behaviors - physically, spiritually, and socially. Nevertheless, the incidence of diabetes mellitus, hereinafter referred to as diabetes, continues to rise (Winasis, 2009). Diabetes is a metabolic disorder caused by glucose disruption within the body. The bodies of individuals with diabetes do not produce a sufficient amount of insulin, thus causing excess glucose within the blood. There are two types of diabetes, type 1 and type 2. Type 1 diabetes often occurs since childhood, whereas type 2 diabetes is more prevalent in those individuals 35 years and older. Diabetes may cause individuals to be more susceptible to infections, such as urinary tract infections, lung infections, and foot infections, and it can cause abnormalities in blood vessels of the retina which could result in blindness. Globally, the number of people with diabetes is 135 million as of 2000, according to the WHO. This number is expected to continue to increase to 366 million people in 2025. At that time, Asia is expected to have the world's largest diabetic population (at 82 million). Indonesia currently ranks fourth largest in the number of people with diabetes in the world.

In Indonesia, type 2 diabetes mellitus is found more frequently than type 1 . The prevalence rate of type 2 diabetes mellitus ranges between $14 \%$ - 16\%. The prevalence rate of diabetes mellitus increases each year. Recent results of epidemiological studies in Indonesia showed similar trend in different cities and regions. Jakarta (the capital city of Indonesia) proved that there was an increased diabetes prevalence from $1.7 \%$ in 1982 to $5.7 \%$ in 1993 , and turn out to be $14.7 \%$ in 2001 . Increased prevalence of diabetes mellitus also occured in Makasar, which increased from $1.5 \%$ in 1981 , to $2.9 \%$ in 1998, and to $12.5 \%$ in 2005. In 2005, West Sumatra reported that they have a diabetes mellitus prevalence of 5.1\%, Pekajangan (Central Java) had 9.2\% while Bali had a diabetes prevalence between $3.9 \%$ - 7.2\% in 2004. According to Rudjianto (2009), Indonesia's pre-diabetes prevalence rate is approximately $21.6 \%$. It was estimated that $50 \%$ of individuals who are in position of pre-diabetes will develop diabetes. Moreover, the highest number of pre-diabetic individuals were found in the age group of 12-17, with a percentage of around 27\% (Rudjianto, 2009).

The increasing tendency of diabetes mellitus, globally, is caused by several factors, which consist of genetic factors, obesity due to lifestyle changes, overeating, lack of exercise, demographics, as well as a reduction in number of infectious disease and malnutrition (Suyono as cited in Soegondo, 2009). Diabetes is capable of striking people of all ages, regardless of whether they reside in rural or urban areas. Health Research Association (Riskesdas) Ministry of Health of Indonesia, in 2007, showed that diabetes was the $2^{\text {nd }}$ leading cause of death of those aged 45-54 in urban areas, causing $14.7 \%$ of deaths. Meanwhile, in rural areas, diabetes ranks in $6^{\text {th }}(5.8 \%)$ in terms of leading cause of death. People with type 2 diabetes generally experience an increase in blood sugar; this increase will trigger a rise in the cortisol, epinephrine, and norepinephrine hormones, leading to depression.

Complications that may occur to diabetics, aside from the disease itself which is degenerative and incurable, is that many of the patients experience anxiety disorders. In a study involving 1456 subjects with diabetes, both type 1 and type 2, from different regions in Ireland, the prevalence rate of those who experience anxiety was $32.0 \%$, and the rate of those who were depressed was $22.4 \%$ (Collins et al., 2008). Studies conducted in Turkey, from 161 subjects with diabetes type 1 and type 2, found that $79 \%$ of the subjects experienced anxiety (Tuncay, Musabak, Gok, \& Kutlu, 2008). In addition to social support, an important factor for people with diabetes is self-acceptance. The better of individual's self acceptance, the lower level of individual's stress.

\subsection{Religiosity - self acceptance - stress}


Illness perception, stress, religiosity, depression, social support, and self management of diabetes in Indonesia

Religiosity and self acceptance were also factors predicted to have the ability to decrease the level of anxiety disorder of individuals with diabetic. Based on the results of research done in the USA, religiosity was able to decrease the anxiety faced by a patient who donated his kidney (Morse et al., 2009). Factors suspected to influence depression include patients' perception on social support and their acceptance of illness. On the other hand, factors expected to affect anxiety include religiosity and self-acceptance.

\subsection{Disease and management perception}

Illness perception is associated with the effectiveness of self management for those who suffer from diabetes (Bean et al., 2007) including a good psychological adaptation for diabetic patients (Gois et al., 2010). Illness perception is also associated with healthy lifestyle and coping behaviour (Keogh et al., 2007). Someone with low control on their diabetes have a different illness perception compared to those with good diabetic control (Keogh et al., 2007).

\subsection{Illness perception}

Illness perception is an individuals' response toward an illness (Leventhal et al. as cited in Keogh et al., 2007) that is formed through the individual's organized perception and conception of their illness base on their experience and environment (Croyle \& Barger as cited in Taylor, 2006). Illness perception is based on Leventhal Self Regulation Model theory which measures five separate components. These components are identity, cause of illness, duration, consequence, and self control (Ogden, 2000), specifically:

A. Identity is the name and symptoms of the disease that relates to the name that was given.

B. The cause of illness is the attribution process that is characterized by the beliefs of why the disease emerged.

C. The duration is the belief of how long the disease may last.

D. Consequence reflects the individuals' hope related to the effect of the illness towards psychological and physical functions.

E. Self control is the belief of how far the disease or symptoms may be controlled and changed by the medicine and health workers.

Illness perception is activated by the long term memory, and the representation is formed based on the comparison between the current incident and the individuals' former belief. Illness perception was employed in many studies to predict the health status of several chronic diseases such as in asthma (Horne \& Weinman, 2002), diabetes (Bean et al., 2007; Lawson et al., 2007), hypertension (Hekler et al., 2008), kidney failure (Timmers et al., 2008), and osteoarthritis (Kaptein et al., 2010). Study on illness perception of people with diabetes showed consistent positive results on adherence (Mann et al., 2009), and coping strategies (Bean et al., 2008; Lawso et al., 2007; Sloan et al., 2009).

\subsection{Coping}

Coping is defined as a cognitive and behavioral process to manage both specific external and internal pressures that are considered heavy or have exceed individuals' resources (Lazarus \& Folkman, as cited in Taylor, 2006). Furthermore, coping consists of efforts, both action-oriented and intra-psychic, in order to manage (master, tolerate, reduce, save time) environmental and internal demands and conflicts among themselves (Lazarus \& Launier as cited in Taylor, 2006).

Coping strategies are predicted to influence the output of self-monitoring; such as glycemic control and psychological factors (depression and anxiety). Research on adults without diabetes showed that 
Yuniarti, K. W., Dewi, C., Ningrum, R. P., Widiastuti, M., \& Asril, N. M.

problem-focused coping has predicted lower levels of HbA1c (Tsenkova et al., 2008). Likewise, a meta-analysis study showed that problem-focused coping is associated with an overall better adjustment, avoidance while emotional-focused coping was not significantly associated with an overall adjustment (Duangdao \& Roesch, 2008).

\subsection{Management}

Essentially, diabetes is a disease that can be controlled. Controlled sugar levels is consistently correlated with a small chance of complications of the disease (Macrodimitris \& Endler, 2001; Waspadji, 2004). Current literature regards diabetes as a process of self-management behavior (Gonder-Frederick et al. as cited in Cox \& Gonder-Frederick, 1992). Self-management of diabetes is a challenging lifetime task and requires high commitment from patients, such as an adherence with diet, regular exercise, take prescription medication and test blood sugar levels regularly (Bean et al., 2007).

Glycemic control is a major goal of diabetes management. Glycemic control is characterized by HbA1c, whereas in general, glycemic control in Indonesia is characterized by "GDN" (Gula Darah Normal, or translated into English literally would be as normal blood sugar) (Sinorita et al., 2008). Riskesdas 2007 results showed that many of those who were diagnosed with diabetes still have uncontrolled blood sugar levels. In $75.9 \%$ of those diagnosed, the glucose levels were higher than $140 \mathrm{mg} / \mathrm{dl}$. Psychologically, research by Hasanat (2008) \& Soeharjono et al. (2002) reported difficulties in the management of diabetes. Meanwhile, a qualitative study conducted by Ningrum (2008) indicated that those with high self-efficacy and strong control in diabetes management were able to maintain a controlled diabetic condition, and conversely, those who succumbed to the management of diabetes had uncontrolled diabetes condition.

Goodall \& Halford review (1991) stated that even if a strong relationship between the effective self-management with glycemic control is found, it does not necessarily mean that good self-management causes good glycemic control. Good response to the management was measured by better controlled blood sugar levels that can be driven by good self-management. The above description shows that there are psychological factors in diabetes management. Treatment strategies are needed to prevent and control diabetes (Bean et al., 2007). Psychological factors are thought to play a role in diabetes management including the illness perception and coping strategies.

\subsection{Social support}

Psychosocial aspects are important elements in a person's diabetes' self-management (Jones et al., 2008). These include the psychosocial aspects of social support, motivation (beliefs and attitudes), and coping skills. Some research on social support suggests that social support effectively reduces psychological burden (Haines et al. as cited in Taylor, 2006), such as depression and anxiety (Taylor, 2006).

Results of research conducted by Fleming et al. (as cited in Taylor, 2006) showed that people with high social support experience lower stress compared to those with low social support. Social support can also reduce the possibility of illness, accelerate recovery from illness, and reduce the risk and serious disease-related mortality (Berkman et al., as cited in Taylor, 2006). In addition, social support plays a role in helping individuals in setting distance themselves or minimizing the occurrence of complications from serious health problems (Taylor, 2006), better adjustment in diabetes, lung disease, heart disease, arthritis, and cancer (Penninx et al., as cited in Taylor, 2006), better control diabetes (Marteau et al., as cited in Taylor, 2006) and increase the prospects of recovery among people who are sick (Wallston et al., in Taylor, 2006). According to the research above, it appears that social support has a strong influence in relation to psychological treatment and adjustment to health and illness. 
Illness perception, stress, religiosity, depression, social support, and self management of diabetes in Indonesia

\section{Hypotheses}

Based on the nature of the study, the proposed and tested hypotheses for each study are as followed:

Study 1:

$>$ There is a negative correlation between perceptions of social support and self-acceptance with depression

$>$ Perceived social support is negatively correlated with depression

$>$ Self Acceptance is negatively correlated with depression

Study 2:

$>\quad$ There is a negative correlation between religiosity and self-acceptance with anxiety

$>$ Religiosity is negatively correlated with anxiety

$>$ Self-acceptance is negatively correlated with anxiety

Study 3:

$>$ There is a positive correlation between illness perception, coping strategies, and self-management diabetes.

$>$ There is a negative correlation between illness perceptions and glycemic control.

$>$ There is a positive correlation between problem-focused coping, self-management, and glycemic control.

$>$ There is a negative correlation between emotional-focused coping and self-management

\section{Methods}

Studies 1, 2 and 3 have similar respondents, all having a total of 65 people, patients with diabetes, male and female, age between 40-75 years old, and was willing to engage in research without coercion by signing an informed consent. Based on the nature of the study, the research instruments used are as the following:

Study 1

A. Depression scale, depression is measured using the Beck Depression Inventory (BDI) in the form of a self report, having 21 categories of depression symptoms.

B. Social Support Perception Scale which covers emotional, instrumental, informational support, and positive feedback.

C. Self-acceptance Scale

Covers 7 general self acceptance indicators, which are:

$>$ The existence of a belief on one's ability in facing problems.

$>$ The notion of self-worth as human being, and perceived equality with others

$>$ The absence of a weird/abnormal presumption of themselves and no hope of being rejected by others

$>\quad$ The absence of shame or lack of attention to oneself

$>$ The existence of courage to take responsibility of one's actions

$>$ The objectivity in receiving compliments/critics

$>$ Does not blame others because of either the limitations that exist or denial of excess

Study 2

A. Anxiety Scale, based on the manifestation of anxiety which was manifested in both the physical and psychological indicators.

B. Religiosity Scale, expressed in the five dimensions of religiosity (religiosity); faith, worship, charity, 
Yuniarti, K. W., Dewi, C., Ningrum, R. P., Widiastuti, M., \& Asril, N. M.

deeds, and science.

C. Self Acceptance Scale, a modification of the self-acceptance scale from Novvida (2007) which was also used in study 1.

Study 3

A. The Brief Illness Perceptions Questionnaire (BIPQ) (Broadbent, Petrie, Main, \& Weinman, 2006), for the illness perception, which measures the dimensions: identity, consequences, duration, personal control, attention, understanding and emotional representations.

B. The Coping Styles Inventory, called COPE (Carver, Scheier, \& Weintraub, 1989) was used to measure coping strategy (Jamaluddin, 2007).

C. Diabetes Self-management Scale developed by Ayusmi (2008), was used to map the respondents self-management

\section{Results and Discussion}

Detailed result and discussion within this study is shown according to the focus of study. Discussion and conclusion of the grand study will be used as the closing remark of this article.

\subsection{Description of Research Subjects}

General overview of the characteristics of research subjects in study 1 can be seen in Table 1 .

\section{Table 1}

The study 1 participants

\begin{tabular}{lcrr}
\hline Socio-demographic & Category & Sample (n) & Frequency (\%) \\
\hline \multirow{2}{*}{ Age } & $40-50$ & 17 & 26.5 \\
& $51-60$ & 28 & 43.08 \\
& $61-70$ & 15 & 23.08 \\
\multirow{2}{*}{ Sex } & $71-75$ & 5 & 7.69 \\
\hline \multirow{2}{*}{ Education } & Female & 45 & 69.23 \\
& Male & 20 & 30.77 \\
\hline \multirow{2}{*}{ Marital status } & Grammar School & 4 & 6.15 \\
& Junior High School & 4 & 6.15 \\
& Senior High School & 32 & 49.23 \\
Residence status & Undergraduate & 5 & 7.69 \\
& Graduate & 20 & 30.77 \\
\hline \multirow{2}{*}{ Duration of illness } & Married & 57 & 87.69 \\
& Widow/Widower & 8 & 12.31 \\
& Unmarried & 0 & 0 \\
\hline \multirow{2}{*}{ Complication } & Single & 2 & 3.08 \\
& Partner/Children/Relative/Grandchildren/Friends & 63 & 96.92 \\
\hline
\end{tabular}

Table 2 shows the descriptive data of the study variables, namely: perception of the social support, self acceptance and depression. 
Illness perception, stress, religiosity, depression, social support, and self management of diabetes in Indonesia

Table 2

Description of variable

\begin{tabular}{lcccccccc}
\hline \multirow{2}{*}{ Variable } & \multicolumn{4}{c}{ Hypothetical } & \multicolumn{4}{c}{ Empirical } \\
\cline { 2 - 9 } & Min & Max & $M$ & $S D$ & Min & Max & $M$ & $S D$ \\
\hline Perception on & 39 & 156 & 97.5 & 16.25 & 87 & 155 & 125.55 & 13.94 \\
Social Support & & & & & & & & \\
Self-acceptance & 29 & 116 & 72.5 & 12.08 & 68 & 108 & 87.20 & 9.02 \\
Depression & 0 & 63 & 31.5 & 5.25 & 0 & 29 & 10.37 & 7.25 \\
\hline
\end{tabular}

Results of the descriptive analysis showed that subjects generally had an average empirical perceived social support (125.55), which was above the hypothetical average (97.5). The subjects also have shown the empirical average of self-acceptance (87.20) was above the hypothetical average (72.5). The empirical mean of subjects on depression scale (10.37) was below the hypothetical average (31.5). Subjects of this study were classified in 3 categories, namely high, medium, and low.

Table 3

Determining of the categories

\begin{tabular}{cc}
\hline Category & Value \\
\hline High & $\mathrm{M}+1 \mathrm{SD} \leq \mathrm{X}$ \\
Medium & $\mathrm{M}-1 \mathrm{SD} \leq \mathrm{X}<\mathrm{M}+1 \mathrm{SD}$ \\
Low & $\mathrm{X}<\mathrm{M}-1 \mathrm{SD}$ \\
\hline
\end{tabular}

Criteria classification was made based on standard deviation and the score of empirical mean of the perception on social support, self acceptance, and depression.

\section{Table 4}

Perceived social support of the study participants

\begin{tabular}{lccc}
\hline \multicolumn{1}{c}{ Category } & Value & Total & Percentage \\
\hline High & $139.49 \leq \mathrm{X}$ & 10 & $15.38 \%$ \\
Medium & $111.61 \leq \mathrm{X}<139.49$ & 45 & $69.23 \%$ \\
Low & $\mathrm{X}<111.61$ & 10 & $15.38 \%$ \\
\hline
\end{tabular}

Table 4 has showed that the perceived social support variables is $139.49 \leq \mathrm{X}$ for the high category, $111.61 \leq$ $\mathrm{X}<139.49$ for the medium category, and $\mathrm{X}<111.61$ for the low category. Based on the description of the data obtained, the empirical mean of the whole subject is 125.55 so it can be estimated that the perceived social support is in the medium category.

Table 5

Categorization Scale of Self Acceptance

\begin{tabular}{lccc}
\hline \multicolumn{1}{c}{ Category } & Value & Total & Percentage \\
\hline High & $96.22 \leq \mathrm{X}$ & 9 & $13.85 \%$ \\
Medium & $78.18 \leq \mathrm{X}<96.22$ & 47 & $72.30 \%$ \\
Low & $\mathrm{X}<78.18$ & 9 & $13.85 \%$ \\
\hline
\end{tabular}

From Table 5, it can be seen that the variable self acceptance has a range of $96.22 \leq \mathrm{X}$ for the high category, $78.18 \leq X<96.22$ for the medium category, and $X<78.18$ for the low category. Based on the description of the data obtained, the empirical mean of the whole subject is 87.20 so it concluded that the subjects' self-acceptance is in the medium category.

From Table 6, it can be seen that the depression variables has a range of $17.62 \leq \mathrm{X}$ for the high category, $3.12 \leq \mathrm{X}<17.62$ for the medium category, and $\mathrm{X}<3.12$ for the low category. Based on the description of the data obtained, the empirical mean of the entire subject is 10.37 so it can be concluded that depression among the 
Yuniarti, K. W., Dewi, C., Ningrum, R. P., Widiastuti, M., \& Asril, N. M.

subject is in the medium category. A total of ten subjects were in the high depression category, and 12 subjects were in the low category.

Table 6

Categorization Scale Depression

\begin{tabular}{lccc}
\hline \multicolumn{1}{c}{ Category } & Value & Total & Percentage \\
\hline High & $17.62 \leq \mathrm{X}$ & 10 & $15.38 \%$ \\
Medium & $3.12 \leq \mathrm{X}<17.62$ & 43 & $66.15 \%$ \\
Low & $\mathrm{X}<3.12$ & 12 & $18.46 \%$ \\
\hline
\end{tabular}

\subsection{Test of hypothesis}

Sobel test was used to see the indirect effect of independent variables on the dependent variable through the mediator variable (Baron \& Kenny, 1986).

Table 7

Analytical Result of Sobel Test Mediation

\begin{tabular}{lcc}
\hline \multicolumn{1}{c}{ Direct and total effect } & Coefficient & $p$ \\
\hline $\mathrm{b}(\mathrm{YX})$ & -0.1662 & 0.0095 \\
$\mathrm{~b}(\mathrm{MX})$ & 0.3132 & 0.0000 \\
$\mathrm{~b}(\mathrm{YM} . \mathrm{X})$ & -0.4482 & 0.0000 \\
$\mathrm{~b}($ YX.M) & -0.0258 & 0.6758 \\
\hline
\end{tabular}

Based on the mediation analysis that the Sobel test obtained, results showed that the "influence" of perceived social support on depression was $\mathrm{b}(\mathrm{YX})=-0.1662, p=0.0095$, which indicates that the perceived social support has a significant role toward depression; a negative correlation was observed. The same was found also between perceived social support on self acceptance as shown in a positive correlation; $b(\mathrm{MX})=0.3132$, $p<0.0001$. The result of the third mediation analysis showed that the effect of self acceptance towards the depression by controlling the perceived social support was $\mathrm{b}(\mathrm{YM} . \mathrm{X})=-0.4482 ; p<0.0001$. It shows that diabetic patients with good self acceptance tend to not experiencing depression or have low levels of depression, with or without social support. Thus, it can be concluded that there is a negative correlation between self-acceptance and depression.

The fourth analysis is the result of the direct effect of perceived social support on the depression, by controlling for self acceptance $\mathrm{b}(\mathrm{YX} . \mathrm{M})=-0.0258 ; p=0.6758$. This indicates that there is no correlation between perceived social supports on depression after controlling self acceptance. It can be concluded that by controlling self acceptance, the perceived social support significantly related towards depression. Result of the Sobel test also showed indirect effect of perceived social support on depression through self acceptance, which is -0.1404; $p=0.0015$. This indicates that perceived social support has a significant role on depression through self acceptance. In other words, self acceptance is the mediator of perceived social support and depression. Perceived social support increases self acceptance before decreasing depression.
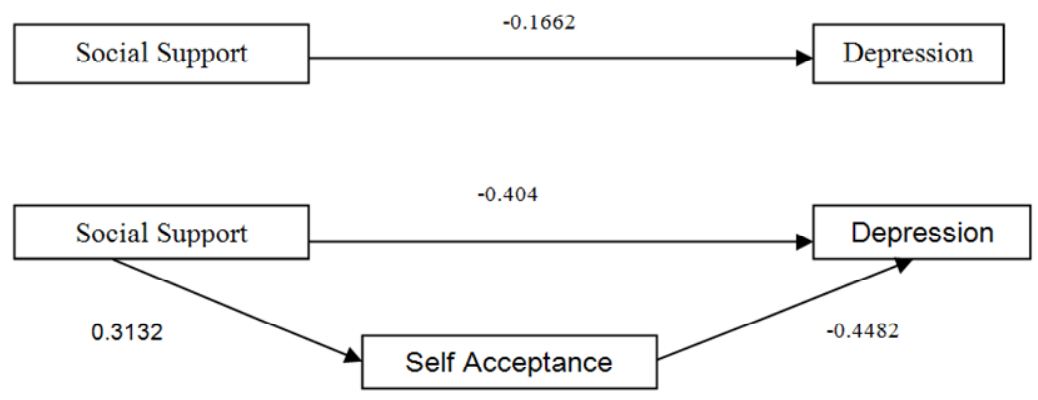

Figure 1 . The diagram of mediation 
Illness perception, stress, religiosity, depression, social support, and self management of diabetes in Indonesia

Hypothesis 1 seemed to be supported, that there is a negative correlation between perceived social support and depression in people with type 2 diabetes. Result of the second stage of Sobel test mediation analysis showed a coefficient of $\mathrm{b}(\mathrm{MX})=0.3132, p<0.0001$, and so hypothesis 2 is accepted, as there is a positive correlation between perceived social support and self acceptance.

The third stage of the Sobel test mediation analysis showed the coefficient result of $b(Y M . X)=-0.4482$; $p<0.0001$. The fourth stage of the Sobel test mediation analysis showed a coefficient of $\mathrm{b}(\mathrm{YX} . \mathrm{M})=-0.0258$; $p=0.6758$. This indicates that there is no significant correlation between perceived social support and depression after controlling self acceptance. Based on the results obtained by the research, it can be concluded that within this study there is a correlation between perceived social support and depression mediated by self acceptance.

There are differences and similarities between the condition of depression among the ten subjects with the highest depression, and the twelve subjects with the lowest depression. Some conditions that were often experienced by the ten subjects with high depression were rarely encountered by the twelve subjects with low depression. These are, for example, on responses related to questions on feeling punished, sleep disorders, and loss of libido. The data showed that subjects experience fatigue, regardless of whether they were in the high depression category or the low depression category. Subjects felt that they get tired easier than before and said that this fatigue is associated with the diabetes. A condition that was equally rarely experienced by subjects with high or low depression was the desire to commit suicide and withdrawal from a social relationship. Subjects rarely had any thoughts of hurting oneself or suicide. Subjects do not lose interest toward others. Subjects within this study, on average still have interest to interact and socialize themselves with others.

\subsection{Result of Study 2}

Table 8 shows the general overview of the respondents from the study 2 .

\section{Table 8}

The study 2 participants

\begin{tabular}{|c|c|c|}
\hline Characteristic & Sample (n) & $(\%)$ \\
\hline \multicolumn{3}{|l|}{ Age } \\
\hline $40-50$ & 29 & 37.18 \\
\hline $51-60$ & 30 & 38.46 \\
\hline $61-70$ & 19 & 24.36 \\
\hline \multicolumn{3}{|l|}{ Sex } \\
\hline Female & 51 & 65.38 \\
\hline Male & 27 & 34.62 \\
\hline \multicolumn{3}{|l|}{ Education } \\
\hline Grammar School & 23 & 29.49 \\
\hline Junior High School & 5 & 6.41 \\
\hline Senior High School & 30 & 38.46 \\
\hline Undergraduate & 11 & 14.10 \\
\hline Graduate & 9 & 11.54 \\
\hline \multicolumn{3}{|l|}{ Duration of Illness } \\
\hline$\leq 2$ years & 22 & 28.21 \\
\hline$\overline{3}-5$ years & 27 & 34.61 \\
\hline $6-10$ years & 15 & 19.23 \\
\hline$>10$ years & 14 & 17.95 \\
\hline \multicolumn{3}{|l|}{ Religion } \\
\hline Islam & 73 & 93.59 \\
\hline Protestant & 2 & 2.56 \\
\hline Catholic & 3 & 3.85 \\
\hline
\end{tabular}

Following are the variables in the study, presented in descriptive table. The table shows that the subject at the average has the empirical values of anxieties about 79.58, which is under the hypothetical average (100). Subjects had a mean empirical religiosity of about 126.9 , which is above the hypothetical average (100). On self 
Yuniarti, K. W., Dewi, C., Ningrum, R. P., Widiastuti, M., \& Asril, N. M. acceptance, subjects had an average empirical value of 87.32, which is above the hypothetical average (72.5).

\section{Table 9}

Description of variable

\begin{tabular}{lcccccccc}
\hline \multirow{2}{*}{ Variable } & \multicolumn{4}{c}{ Hypothetical } & \multicolumn{4}{c}{ Empirical } \\
\cline { 2 - 9 } & Min & Max & $M$ & $S D$ & Min & Max & $M$ & $S D$ \\
\hline Anxiety & 40 & 160 & 100 & 16.67 & 57 & 108 & 79.58 & 13.591 \\
Reliogiousity & 48 & 152 & 100 & 16.67 & 113 & 145 & 126.9 & 9.169 \\
Self-acceptance & 29 & 116 & 72.5 & 12.08 & 71 & 103 & 87.32 & 8.056 \\
\hline
\end{tabular}

\subsection{Test of hypothesis}

Similar to Study 1, Study 2 also used the Sobel test for mediation analysis (Baron \& Kenny, 1986; Preacher \& Hayes, 2004).

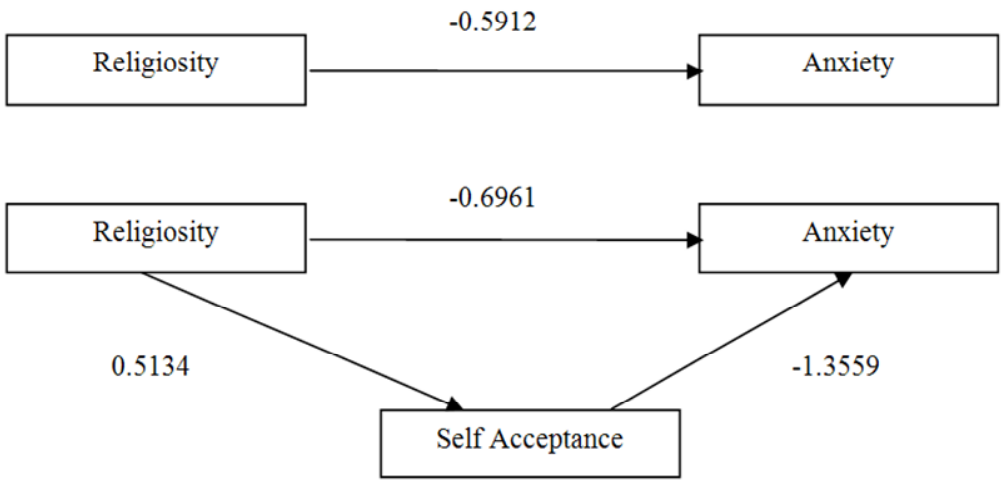

Figure 2. The diagram of mediation

Results of the mediation analysis showed that there is a significant negative correlation between religiosity and anxiety $(\mathrm{b}(\mathrm{YX})=-0.5912$; and $p<0.05)$ Similar result was found by Morse et al. (2009), which showed that religiosity is related to anxiety that was experienced by patients with chronic disease. Other research stated that a good base of religiosity was associated with the declining level of anxiety they felt (Khalek, 2006). Koenig later explained that religiosity represented the source of power that came through comfort, hope, and meaningfulness (Koenig, 2009).

The results of the second analysis showed that there is a highly significant positive correlation between religiosity and self-acceptance $(\mathrm{b}(\mathrm{MX})=0.5134, p<0.01)$. Data also showed that there was a significant positive correlation between religiosity with self-acceptance, and there is a significant negative correlation between self-acceptance and anxiety $(\mathrm{b}(\mathrm{YM} . \mathrm{X})=-1.3599, p<0.01)$. Indirect effect of religiosity on anxiety through self acceptance, indicated in the Sobel test about $-0.6961, p<0.01)$. This suggests that religiosity has a very significant role on anxiety through self-acceptance. Self-acceptance mediated the relation between religiosity and anxiety.

Anxiety was highest in the experience of the subjects in relation to things that affect the stamina of the subject in work. The subjects became more fatigued compared to when they were healthy. A total of 35 subjects (44.9\%) claimed that ever since they caught diabetes, they were more susceptible to fatigue while working. Paddison et al. (2011) stated that people, when first being diagnosed with diabetes, had high levels of anxiety.

\subsection{Result of Study 3}

In general, the characteristics of the research subjects can be seen in Table 10 below: 
Illness perception, stress, religiosity, depression, social support, and self management of diabetes in Indonesia

Table 10

The study 3 participants

\begin{tabular}{|c|c|c|}
\hline Characteristic & Sample (n) & $(\%)$ \\
\hline \multicolumn{3}{|l|}{ Age } \\
\hline $40-50$ & 4 & 6.6 \\
\hline $51-60$ & 28 & 45.9 \\
\hline $61-70$ & 29 & 47.5 \\
\hline \multicolumn{3}{|l|}{ Sex } \\
\hline Female & 37 & 60.7 \\
\hline Male & 24 & 39.3 \\
\hline \multicolumn{3}{|l|}{ Education } \\
\hline Grammar School & 8 & 13.1 \\
\hline Junior High School & 9 & 14.8 \\
\hline Senior High School & 21 & 34.4 \\
\hline College & 23 & 37.7 \\
\hline \multicolumn{3}{|l|}{ Duration of Illness } \\
\hline 6 months- 2 years & 22 & 36.1 \\
\hline $3-5$ years & 16 & 26.2 \\
\hline $6-10$ years & 10 & 16.4 \\
\hline$>10$ years & 13 & 21.3 \\
\hline
\end{tabular}

\section{Table 11}

Descriptive data of illness perception and self-management $(n=61)$

\begin{tabular}{lcccc}
\hline \multicolumn{1}{c}{ Variables } & Range of scores & $\begin{array}{c}\text { Range of } \\
\text { empirical score }\end{array}$ & SD & Mean \\
\hline Illness Perception & $0-13$ & $0-13$ & 3.000 & 4.00 \\
$\quad$ Identity & $6-30$ & $7-25$ & 4.316 & 17.74 \\
Timeline acute/chronic & $3-15$ & $6-15$ & 1.883 & 10.59 \\
Timeline cycle & $6-30$ & $6-26$ & 3.981 & 16.18 \\
Consequences & $4-20$ & $7-20$ & 2.446 & 15.18 \\
Personal control & $5-25$ & $14-25$ & 1.975 & 18.97 \\
Treatment control & $5-25$ & $10-24$ & 3.500 & 16.13 \\
Understanding of pain & $6-30$ & $9-24$ & 3.621 & 15.41 \\
Emotional representation & $26-104$ & $58-100$ & 10.000 & 82.00 \\
Self Management & &
\end{tabular}

Three of the most important factors that the subjects believe to be the cause of their diabetes can be seen in table 12 as followed:

\section{Table 12}

Causes of Diabetes

\begin{tabular}{lccc}
\hline \multicolumn{1}{c}{ Possible causes of Diabetes } & $\begin{array}{c}\text { Number of subjects } \\
(\%) \text { as the 1st cause }\end{array}$ & $\begin{array}{c}\text { Number of subjects } \\
(\%) \text { as the 2nd cause }\end{array}$ & $\begin{array}{c}\text { Number of subjects } \\
(\%) \text { as the 3rd cause }\end{array}$ \\
\hline Eating habit & 41.0 & 31.1 & 6.6 \\
Genetics & 32.8 & 6.6 & 1.6 \\
My own behavior* & - & 16.4 & 8.2 \\
Stress or anxiety & 8.2 & 8.2 & 8.2 \\
Aging & 1.6 & 3.3 & 6.6 \\
Overworked & 1.6 & 4.9 & 3.3 \\
My mental attitude, such as negative & - & - & 8.2 \\
thoughts on life & - & 1.6 & 1.6 \\
Emotional state, such as falling down, & - & 1.6 & - \\
worry, empty & 1.6 & - & 8.2 \\
Immune & - & - & \\
Family problems & - & \\
God's will & Note. My own behavior includes lack of exercise and unhealthy lifestyle & & \\
\hline
\end{tabular}


Table 12 shows that diabetic patients believe the main cause of their diabetes are eating habit (41\%), genetic $(32.8 \%)$, while $8.2 \%$ believe that it is caused by stress and anxiety. The second cause believed causing diabetes by the subjects of the study are eating habits $(31.1 \%)$, my own behavior, including lack of exercise, and unhealthy lifestyle (16.4\%), and stress of worry $(8.2 \%)$. The third factors believed by the patients to cause their diabetes are their own behavior (8.2\%), stress of worry (8.2\%), mental attitude (negative thinking on life) $8.2 \%$, and lastly that the illness is meant from God (8.2\%). Pearson product-moment correlation was used to ascertain whether there is a significant correlation between variables in the study. Table 13 shows that there is a positive correlation between identification with the understanding of pain $(\mathrm{r}=0.249, p<0.05)$, negative correlation timeline acute / chronic to treatment controls $(\mathrm{r}=-0.279, p<0.05)$. This indicates that people with diabetes who view the disease as more chronic than acute lead individuals to believe on the effectiveness of the treatment or management.

The consequences of diabetes negatively correlated with both, treatment control and understanding of illness $(p<0.01)$. This indicates that people with diabetes that view the illness as serious and impacts their lives, cannot determine whether or not the management can be effectively performed. The better patients understand their illness, the more they can minimize the consequences of diabetes. Representation of positive emotions correlate well with the cyclical timeline and consequence $(p<0.001)$. This indicates that the symptoms are intermittent with no predictable time of appearance, sometimes better sometimes worse and seriousness of the disease that bears the representation of negative emotion display for people with diabetes.

It is showed that only treatment controls is correlated with problem-focused coping $(\mathrm{r}=0.280, p<0.01)$ and emotional-focused coping is positively correlated with the consequences and personal control $(p<0.05)$. Table 14 shows the regression analysis of the variables. It is only one significant correlation that met the criteria for mediation analysis, the independent variable relationship with the mediator variable, the other 2 relationships are not significantly correleted. In other words, a hypothesis cannot be tested because the requirement of mediation analysis was not fulfilled. Table 14 showed other findings, namely the treatment control correlated with problem focused coping ( $\mathrm{F}=5.033, p<0.05)$, correlated with the emotional focused coping $(\mathrm{F}=4.234, p<0.05)$ and correlated with emotional personal control focused coping $(\mathrm{F}=4.475, p<0.05)$.

Result found no significant correlation between coping strategies with self-management. In other words, hypothesis 3 is rejected. This finding is different from the results of previous studies, namely the problem focused coping, proactive coping was positively correlated with self-adjustment and self-management (Duangdao \& Roesch, 2008; Hart, 2006; Thoolen et al., 2009), while emotion focused coping was negatively correlated with self-management, especially the routine examination (Lawson et al., 2007).

Only three out of the eight dimensions of illness perception are correlated with coping strategies, namely the treatment control which is positively correlated with problem focused coping and consequences of personal control which are correlated with emotion focused coping. These findings are consistent with previous research which stated that the stronger the belief in the effectiveness of treatment associated with more use of active coping and seeking instrumental support. Meanwhile, the consequences is correlated with emotion focused coping (Lawson et al., 2007). Mediation analysis to test the first hypothesis cannot be run. There is only one significant correlation, i.e. the illness perception with coping strategies. Since there is only one criterion for mediation analysis of Baron and Kenny (1986), especially direct connection and the illness perception self-management is not significant then the mediation did not occur.

Results showed that most people with diabetes attributed the main cause of illness as a result of risk factors [eating habits $(41 \%)$, unhealthy behaviors $(16.4 \%)$, heredity $(32 \%)$ ]. This is consistent with the medical model of the causes of diabetes, namely the development of insulin resistance caused by lifestyle factors (such as eating habits and other unhealthy behaviors) that interact with genetic factors (hereditary) (Gomersall et al., 2011; Suyono, 2004). This study found that people with diabetes looked at the causes were more atributted to psychological risk factors, such as stress or fear $(8.2 \%)$. The same thing was found in a qualitative study of 
Illness perception, stress, religiosity, depression, social support, and self management of diabetes in Indonesia

Adam (as cited in Gomersall et al., 2011) having a sample of Latin female participants, looked at the causes of diabetes due to stress. Based on the bio-psychosocial model, stress was not directly related to the rise in blood glucose levels but rather through the psychophysiology (Peyrot et al., 1999). Nevertheless, the discussion in the literatures on stress was associated with self-management and glycemic control, not as the cause of diabetes (Goodall \& Halford, 1991; Peyrot et al., 1999).

\section{Table 13}

Correlation between Illness Perception, Coping Strategy, and Self Management

\begin{tabular}{|c|c|c|c|c|c|c|c|c|c|c|c|}
\hline Items & 1 & 2 & 3 & 4 & 5 & 6 & 7 & 8 & 9 & 10 & 11 \\
\hline 1 & - & $0.269^{*}$ & -0.228 & 0.090 & -0.109 & -0.090 & $0.249 *$ & -0.162 & 0.037 & 0.075 & -0.085 \\
\hline 2 & & - & 0.081 & 0.131 & -0.035 & $-0.279 *$ & -0.015 & 0.036 & 0.084 & 0.010 & -0.052 \\
\hline 3 & & & - & $0.366^{*}$ & -0.107 & 0.001 & $0.237 *$ & $0.414 * * *$ & 0.184 & 0.158 & 0.109 \\
\hline 4 & & & & - & -0.111 & $-0.313 * *$ & $-0.298 * *$ & $0.420 * * *$ & 0.062 & $0.259 *$ & -0.034 \\
\hline 5 & & & & & - & $0.439 * * *$ & -0.016 & 0.074 & 0.180 & $0.268^{*}$ & -0.193 \\
\hline 6 & & & & & & - & $0.309 * *$ & -0.152 & $0.280 * *$ & 0.069 & -0.010 \\
\hline 7 & & & & & & & - & $-0.492 * * *$ & -0.006 & 0.065 & 0191 \\
\hline 8 & & & & & & & & - & 0.069 & 0.090 & 0.016 \\
\hline 9 & & & & & & & & & - & $0.548 * * *$ & 0.147 \\
\hline 10 & & & & & & & & & & - & 0.202 \\
\hline 11 & & & & & & & & & & & - \\
\hline
\end{tabular}

Another interesting finding was partly attributed the causes of ill people with diabetes as the will of God (8.2\%). Attribution emerged as a cultural difference about the beliefs of diabetes mellitus (Barnes as cited in Moss-Morris et al., 2002). Furthermore, the attribution of the will of God as the cause of the diabetes was reinforced the results of previous qualitative studies. The study results of Ningrum (2008), Asril (2011) reflected that the subject realized that the main cause of illness was due to diabetes risk factors. When the subjects finally got diagnosed having diabetes, then it has become "the will of God". Meta-synthesis studies by Gomersall et al. (2011) showed that the presence of cultural influences in diabetes self-management, e.g. participants Muslim Pakistan and India that have a view of diabetes as the will of God to be passive in the approach to illness.

Identity dimension revealed the symptoms related to diabetes. Results of this study showed that there were diabetic patients without symptoms while there were also those who have several symptoms. These symptoms indicate the condition during hypoglycemia as well as during hyperglycemia. This study found that diabetics tend to perceive their illness as a chronic or aging illness. This can be seen from how long the disease lasted after getting diagnosed for decades. The condition of diabetes cannot be predicted, sometimes it gets better and other times it gets worse or even cyclical. This is supported by their strong belief to be able to control their illness. Illness perception is consistent with chronic diabetes model and requires complex management (Gonder-Frederick et al., 2002; Waspadji, 2004). The consequences of diabetes are negalively correlated with treatment control. This is in line with the findings of Griva et al. (2000). The consequences of diabetes correlated with the representation of emotion. These findings are consistent with previous studies which stated that the consequences associated with emotional responses (Talbot et al., as cited in Skinner et al., 2002).

\section{General Conclusions}

Results of the studies showed that self-acceptance is associated with depression $(\mathrm{r}:-.14, p<.05)$ without any mediation of social support (r: -.16, $p>.05)$. Medium religiosity has a significant correlation with stress (r: -.69, $p<.05$ ), with the mediation of self-acceptance (r: -.36, $p<.05$ ). Most subjects (more than 50\%) identified the root of the main stressor is lack of stamina such as getting tired faster during work, compared to the time before getting diabetes. This study also showed that the illness perception and coping strategies are not correlated directly, nor with self-management. The partial analysis found that problem-focused coping is associated with 
Yuniarti, K. W., Dewi, C., Ningrum, R. P., Widiastuti, M., \& Asril, N. M.

general self management, medium emotion-focused coping correlated with the consequences of illness and personal control. The study is by no means pecfect. There are limitations of the study, such as the suspicion of multicolinerity between the components of illness perception that has 8 sub-components, coping strategies, and self-management. The sample size was not that big for running Sobel test, and the precision of the test can be limited, and so does the external validity. Important conclusion of this study is that self acceptance is very important, compared to social support, medium religiosity is a possible reinforcement towards self-acceptance, either for one-self or the family and the environment (schools, families, and communities).

\section{Table 14}

Regression analysis of Illness perception, coping strategy, and self management

\begin{tabular}{|c|c|c|c|c|}
\hline Items & $\mathrm{R}^{2}$ & $\beta_{0}$ & $\beta_{1}$ & Significance \\
\hline Illness Perception & \multicolumn{4}{|c|}{ Self management } \\
\hline Identity & 0.007 & 83.277 & -0.319 & ns \\
\hline Timeline acute/chronic & 0.003 & 84.223 & -0.122 & ns \\
\hline Timeline cycle & 0.012 & 75.911 & 0.581 & ns \\
\hline Consequence & 0.001 & 83.439 & -0.085 & ns \\
\hline Personal control & 0.037 & 94.104 & -0.793 & ns \\
\hline Treatment control & 0.000 & 83.028 & -0.051 & ns \\
\hline Understanding of Illness & 0.036 & 73.232 & 0.548 & ns \\
\hline Emotional representation & 0.000 & 81.373 & 0.045 & ns \\
\hline Illness Perception & \multicolumn{4}{|c|}{ Problem focused coping } \\
\hline Identity & 0.001 & 14.981 & 0.031 & ns \\
\hline Timeline acute/chronic & 0.007 & 14.328 & 0.043 & ns \\
\hline Timeline cycle & 0.034 & 12.786 & 0.218 & ns \\
\hline Consequence & 0.004 & 14.538 & 0.035 & ns \\
\hline Personal control & 0.032 & 12.607 & 0.164 & ns \\
\hline Treatment control & 0.079 & 9.083 & 0.317 & $p<0.05$ \\
\hline Understanding of Illness & 0.000 & 15.160 & -0.004 & ns \\
\hline Emotional representation & 0.005 & 14.441 & 0.013 & ns \\
\hline Illness Perception & \multicolumn{4}{|c|}{ Emotion focused coping } \\
\hline Identity & 0.006 & 37.939 & 0.137 & ns \\
\hline Timeline acute/chronic & 0.000 & 33.263 & 0.011 & ns \\
\hline Timeline cycle & 0.025 & 34.105 & 0.411 & ns \\
\hline Consequence & 0.067 & 33.305 & 0.319 & $p<0.05$ \\
\hline Personal control & 0.072 & 30.300 & 0.537 & $p<0.05$ \\
\hline Treatment control & 0.005 & 35.222 & 0.171 & ns \\
\hline Understanding of Illness & 0.004 & 36.981 & 0.092 & ns \\
\hline Emotional representation & 0.008 & 36.588 & 0.121 & ns \\
\hline \multicolumn{5}{|c|}{ Self management } \\
\hline Problem focused coping & 0.022 & 72.101 & 0.660 & ns \\
\hline Emotion focused coping & 0.041 & 66.183 & 0.413 & ns \\
\hline
\end{tabular}

Note $. \mathrm{ns}=$ not significant

Acknowledgement: This study was part of an integrated study on Management Diabetes Mellitus supported through a Hibah Grant by the Faculty of Psychology, Universitas Gadjah Mada, Yogyakarta, Indonesia (Hibah Payung Magister Profesi Psikologi, Fiscal Year 2011).

\section{References:}

Asril, N. M. (2011). Experiencing and managing type 1 diabetes mellitus for adolescents in Indonesia: An integrated phenomenology and indigenous psychological analysis [In Indonesian]. Unpublished Masteral thesis, Universitas Gadjah Mada, Indonesia. 
Illness perception, stress, religiosity, depression, social support, and self management of diabetes in Indonesia

Ayusmi, W. (2008). Stress management training to improve self-management for people with type 2 diabetic [In Indonesian]. Unpublished Masteral thesis, Universitas Gadjah Mada, Indonesia.

Baron, R. M., \& Kenny, D. A. (1986). The moderator-mediator variable distinction in social psychological research: Conceptual, strategic, and statistical consideration. Journal of Personality and Social Psychology, 51(6), 1173-1182. <http://dx.doi.org/10.1037/0022-3514.51.6.1173>

Bean, D., Cundy, T., \& Petrie, K. (2007). Ethnic differences in illness perceptions, self-efficacy, and diabetes self-care. Psychology and Health, 22(7), 787-811. <http://dx.doi.org/10.1080/14768320600976240>

Broadbent, E., Petrie, K. J., Main, J., \& Weinman, J. (2006). The brief illness perception questionnaire. Journal of Psychosomatic Research, 60, 631- 637. <http://dx.doi.org/10.1016/j.jpsychores.2005.10.020>

Carver, C. S., Scheier, M. F., \& Weintraub, J. K. (1989). Assessing coping strategies: A theoretically based approach. Journal of Personality and Social Psychology, 56(2), 267-283. $<$ http://dx.doi.org/10.1037/0022-3514.56.2.267>

Collins, M. M., Corcoran, P., \& Perry, I. J. (2008). Psychology anxiety and depression symptoms in patients with diabetes. Sonora, CA: University of California Cooperative Extension.

Cox, D. J., \& Gonder-Frederick, L. (1992). Major developments in behavioral diabetes research. Journal of Consulting and Clinical Psychology, 60, 628-638. <http://dx.doi.org/10.1037/0022-006X.60.4.628>

Duangdao, K. M., \& Roesch, S. C. (2008). Coping with diabetes in adulthood: a meta-analysis. Journal Behavior Medicine, 31, 291-300. <http://dx.doi.org/10.1007/s10865-008-9155-6>

Gomersall, T., Madill, A., \& Summers, L. K. M. (2011). A meta-synthesis of the self-management of type 2 diabetes. Qualitative Health Research, 21(6), 853-871. <http://dx.doi.org/10.1177/1049732311402096>

Goodall, T. A., \& Halford, W. K. (1991). Self-management of diabetes mellitus: A critical review. Health Psychology, 70(1), 1-8. <http://dx.doi.org/10.1037/0278-6133.10.1.1>

Griva, K., Myers, L.B., \& Newman, S. (2000). Illness perceptions and self efficacy beliefs in adolescent and young adult with insulin dependent diabetes mellitus. Psychology and Health, 15, 733-750. <http://dx.doi.org/10.1080/08870440008405578>

Hasanat, N. U. (2008). The psychological aspect of Pasien Diabetes Melitus patients and their families in Diabetes Melitus management: A exploration study [In Indonesian]. An unpublished study report, Universitas Gadjah Mada, Indonesia.

Hekler, E. B., Lambert, J., Leventhal, E., Leventhal, H., Jahn, E., \& Contrada, R. J. (2008). Commonsense illness beliefs, adherence behaviors, and hypertension control among African Americans. Journal of Behavioral Medicine, 31, 391-400. <http://dx.doi.org/10.1007/s10865-008-9165-4>

Horne, R., \& Weinman, J. (2002). Self-regulation and self-management in Asthma: Exploring the role of illness perception and treatment belief in explaining non adherence to preventer medication. Psychology and Health, 17(1), 17-32. <http://dx.doi.org/10.1080/08870440290001502>

Jamaluddin, M. (2007). The stress coping strategy used by patients with diabetes mellitus with self-monitoring as the mediating variable [In Indonesian]. Unpublished masteral thesis, Universitas Gadjah Mada, Indonesia.

Bernard et al. (2008). Self-management education: Canadian diabetes association clinical practice guidelines expert committee. Canadian Journal of Diabetes, 32, Supplement 1.

Kaptein, A. A., Bijdterbosch, J., Scharloo, M., Hampson, S. E., Kroon, H. M., \& Kloppenburg, M. (2010). Using commonsense model illness perception to examine osteoarthritis: A 6-years longitudinal study. Health Psychology, 29(1), 56-64. <http://dx.doi.org/10.1037/a0017787>

Keogh, K. M., White, P., Smith, S. M., McGilloway, S., O’Dowd, T., \& Gibney, J. (2007). Study protocol changing illness perceptions in patients with poorly controlled type 2 diabetes: A randomised controlled trial of a family-based intervention: protocol and pilot study. BMC Family Practice, 8, 36. $<$ http://dx.doi.org/10.1186/1471-2296-8-36>

Lawson, V. L, Lyne, P. A, Bundy, C., \& Harvey, J. N. (2007). The role of illness perceptions, coping, and evaluation in care-seeking among people with type 1 diabetes. Psychology and Health, 22(2), 175-191. <http://dx.doi.org/10.1080/14768320600774546>

Koenig, H. G. (2009). Research on religion, spirituality, and mental health. The Canadian Journal of Psychiatry, 
54(5), 283-291.

Mann, D. M., Ponieman, D., Leventhal, H., \& Halm, E. A. (2009). Predictor of adherence to diabetes medication: the role of disease and medication belief. Journal of Behavioral Medicine, 32, 278-284.

$<$ http://dx.doi.org/10.1007/s10865-009-9202-y>

Morse, C. R., Afifi, W. A., Morgan, S. E., Stephenson, M. E., Reichert, T., Harrison, T. R., \& Long, S. D. (2009). Religiosity, anxiety, and discussions about organ donation: Understanding a complex system of associations. Health Communication, 24, 156-164. <http://dx.doi.org/10.1080/10410230802676755>

Moss-Morris, R., Weinman, J., Petrie, K. J., Horne, R., Cameron, L. D., \& Buick, D. (2002). The revised illness perception questionnaire (IPQ-R). Psychology and Health, 17(1), 1-16. $<$ http://dx.doi.org/10.1080/08870440290001494>

Ningrum, R. P. (2008). The dynamics of self-regulation in patients with type 2 diabetes mellitus - A qualitative study [In Indonesian]. Unpublished thesis, Universitas Gadjah Mada, Indonesia.

Novidda, K. (2007). Self acceptance and stress in diabetes mellitus patients [In Indonesian]. Unpublished thesis, Universitas Islam Indonesia, Indonesia.

Ogden, J. (2000). Health psychology: A text book (2 $2^{\text {nd }}$ ed.). Buckingham: Open University Press.

Paddison, C. A. M, Eborall, H. C., French, D. P., Kinmonth, A. L., Prevost, A. T., Griffin, S. J., \& Sutton, S. (2011). Predictors of anxiety and depression among people attending diabetes screening: A prospective cohort study embedded in the Cambridge) randomized control trial. British Journal of Health Psychology, 16, 213-226. <http://dx.doi.org/10.1348/135910710X495366>

Peyrot, M., McMurry, J. F., \& Kruger, D. F. (1999). A biopsychosocial model of glycemic control in diabetes: Stres, coping, and regimen adherence. Journal of Health and Social Behavior, 40(2), 141-158. $<$ http://dx.doi.org/10.2307/2676370>

Rudijianto, A. (2009). Management diabetes [In Indonesian]. An unpublished paper presented at the conference of World of Diabetes Day.

Sinorita, H., Saádah, \& Jazakillah, S. (2008). Effect of dietary pattern and education on glycemic control on patient with type 2 diabetes mellitus at Dr. Sardjito Central General Hospital, Yogyakarta. Acta medica Indonesiana, 40(2), 55-58.

Skinner, T. C., Hampson, S. E., \& Fife-Schaw, C. (2002). Personality, personal model beliefs, and self care in adolescent and young adults with type 1 diabetes. Health Psychology, 21(1), 61-70. $<$ http://dx.doi.org/10.1037/0278-6133.21.1.61>

Sloan, F. A., Padron, N. A., \& Platt, A. C. (2009). Preference, beliefs, and self-management of diabetes. Health Research and Educational Trust, 44(3), 1068-1087.

Soeharjono, L. B., Tjokropawiro, A., \& Adi, S. (2002). Insulin Dependent Diabetes Mellitus (DMTI): The psychological aspects of patients and their families [In Indonesian]. Anima, Indonesian Psychological Journal, 17(2), 161-169.

Suyono, S. (2004). The Tendency in The Total Improvement in The Patients with Diabetes in S. Soegondo, P. Soewondo, \& I. Subekti (Eds), The integrated administration of Diabetes Mellitus [In Indonesian]. Jakarta: Balai Penerbit FKUI.

Taylor, S. E. (2006). Health Psychology (6th ed.). New York: McGraw-Hill.

Timmers, L., Thong, M., Dekker, F. W, Boeschoten, E. W., Heijmans, M., Rijken, M., Weinman, J., \& Kaptein, A. (2008). Illness perceptions in dialysis patients and their association with quality of life. Psychology and Health, 23(6), 679-690. <http://dx.doi.org/10.1080/14768320701246535>

Thoolen, B. J., de Ridder, D., Bensing, J., Gorter, K., \& Rutten, G. (2009). Beyond good intentions: The role of proactive coping in achieving sustained behavioural change in the context of diabetes management. Psychology and Health, 24(3), 237-254. <http://dx.doi.org/10.1080/08870440701864504>

Tsekonva, V., Love, G. D, Singer, B. H, \& Ryff, C. D. (2008). Coping and positive affect predict longitudinal change in glycosylated hemoglobin. Health Psychology, 27(2), 163-171. $<$ http://dx.doi.org/10.1037/0278-6133.27.2(Suppl.).S163>

Tuncay, T., Musabak, I., Gok, D. E., \& Kutlu, M. (2008). The relationship between anxiety, coping strategies and characteristics of patients with Diabetes. Health and Quality of Life Outcomes, 6, 79. 
Illness perception, stress, religiosity, depression, social support, and self management of diabetes in Indonesia

$<$ http://dx.doi.org/10.1186/1477-7525-6-79>

Waspadji, S. (2004). Diabetes Melitus: The basic mechanism and the rational management. In DKK. Soegondo

(Ed.), The integrated administration of Diabetes Mellitus [In Indonesian]. Jakarta: Fakultas Kedokteran Universitas Indonesia.

Winasis, E. B. (2009). The correlation between self-concept and depression in patients with Diabetes Mellitus in Puskesmas Pracimantoro I Wonogiri [In Indonesian]. Unpublished thesis, Universitas Muhammadiyah Surakarta, Indonesia. 
Yuniarti, K. W., Dewi, C., Ningrum, R. P., Widiastuti, M., \& Asril, N. M. 